\title{
América latina ante la pax mafiosa: Entre la confusión y la indiferencia
}

\author{
Latin America and the pax mafiosa: \\ between perplexity and indifference
}

—uan Gabriel Tokatlian ${ }^{\star}$

\section{UN GRAN DESAFÍO}

Latinoamérica afronta múltiples y enormes desafíos políticos: por ejemplo, la reconstrucción y relegitimación del estado fallido en Haití, una transición política incruenta pos-Castro en Cuba, la coexistencia con una Venezuela radicalizada en democracia, la persistencia del conflicto armado en Colombia, el fortalecimiento pacífico y recursivo del débil Estado en Bolivia, la preservación de una frágil democracia en Paraguay, la superación de crecientes escaramuzas diplomáticas (entre Argentina y Uruguay, entre Chile y Perú, entre Chile y Bolivia, entre Brasil y Bolivia, entre Colombia y Venezuela, entre Ecuador y Colombia, entre Venezuela y México, etc.) y el no deslizamiento hacia nuevas carreras armamentistas zonales.
Ahora bien, a todos esos retos, de por sí significativos por su dimensión específica y su simultaneidad temporal, se suma el peligroso encumbramiento de una pax mafiosa a lo largo y ancho de la región; es decir, al crecimiento y consolidación de una nueva clase social criminal con capacidad hegemónica ante la desorientación de las elites dirigentes, la parálisis de la sociedad civil, el desvanecimiento del Estado y el desdén de la comunidad internacional. Esta pax mafiosa se deriva de un fenómeno medular: el lucrativo negocio de las sustancias psicoactivas ilícitas. La política prohibicionista vigente ha conducido a que hoy exista en el mundo una extraordinaria variedad de drogas naturales y sintéticas, que se demanden y obtengan estupefacientes a menor precio y con mayor pureza, y que se haya gene-

\footnotetext{
"Profesor de Relaciones Internacionales, Universidad de San Andrés, Argentina.
} 
rado una sofisticada criminalidad organizada que opera con más influencia y recursos que muchos Estados; en especial en Latinoamérica.

Por lo general, existe una la multiplicidad de términos para definir a la criminalidad organizada. Hay concepciones disciplinarias sobre el tema. Son diversas las aproximaciones a su naturaleza. También resultan variados los enfoques para hacerle frente. No obstante esta pluralidad, hoy prevalece un relativo consenso entre estudiosos y expertos sobre ciertas características básicas del crimen organizado. Así se distinguen, al menos, las siguientes:

Primero, el crimen organizado es un fenómeno que se circunscribe cada vez menos a un único espacio físico, a un solo grupo nacional y a un número reducido de productos en control de una organización. Por el contrario, asistimos a una forma empresarial delictiva que, en su evolución, se ha mostrado fértil y diversa. En efecto, al analizar los bienes y servicios ilícitos y clandestinos que se ofrecen en el mercado, las bandas que los manejan, los conjuntos humanos que los comercializan, la variedad de públicos que los consumen; la multiplicidad de estructuras legales e ilegales que se nutren de la criminalidad organizada, es posible aseverar que ésta se encuentra en un proceso de mutación. Por ello, el alcance del crimen organizado es integral, es decir, ha adquirido dimensiones globales (en lo geográfico), transnacionales (en lo étnico y cultural), multiformes (en los acuerdos que forja con sectores políti- cos y sociales) y pluriproductivas (en cuanto a la abundancia de productos que transa).

Segundo, la criminalidad organizada se asienta en un contexto en el que las relaciones individuales y colectivas facilitan su maduración. El crimen organizado es mucho más que un acto de anomia o un comportamiento presuntamente desviado. Esta modalidad de crimen se inserta en una compleja matriz en la que la sociedad es al mismo tiempo víctima de sus demostraciones violentas de fuerza y beneficiaria de los bienes y servicios que provee. Además, surge y se ramifica en un entorno en el que el Estado se encuentra, parcial o completamente, tácita o expresamente, según el caso, en connivencia con dicha criminalidad permitiendo que su capacidad operativa prospere sin freno efectivo. En consecuencia, el escenario en que se desarrolla el crimen organizado es el de una subcultura funcional a su expansión y en el que muy pocos, dentro y fuera del Estado, acatan las políticas públicas para su contención inicial y posterior erradicación.

Tercero, una constante observable en las distintas experiencias históricas es la búsqueda de poder político y económico por parte del crimen organizado. En el nivel local, nacional y mundial, a partir de diferentes bienes y servicios ilegales, de modo más o menos violento, la criminalidad organizada pretende garantizar e incrementar sus ganancias, su incidencia y su seguridad. De allí que el objeto último del crimen 
organizado sea asegurar su dominación social. Si bien la amenaza y el uso de la fuerza, así como el soborno y la corrupción son elementos distintivos del crimen organizado, la violencia no es el único medio que lo caracteriza. La criminalidad organizada tiene la necesidad, la oportunidad y la capacidad para combinar coerción y consenso. Su vigencia no radica solo en la provocación del temor, sino también en la búsqueda del reconocimiento de la población. Esto evidencia la posibilidad y el interés de la criminalidad de convertirse en un actor social con potencialidad hegemónica.

Cuarto, la criminalidad organizada no responde a un patrón rígido de conformación y conducta. El crimen organizado se apoya en redes, coaliciones y asociaciones de distinta índole, pero no constituye un tipo de cartel o conglomerado monolítico. Los lazos familiares, regionales, culturales, étnicos, generacionales, religiosos y nacionales son esenciales y se yuxtaponen con formas de agrupación y alianza múltiples. Pueden presentarse casos más cerrados o abiertos de aglutinación de vínculos criminales. De hecho, los ejemplos actuales muestran una tendencia hacia diversos esquemas híbridos de agrupamiento y acción. En ellos predomina un hilo conductor relativamente semejante: una visión práctica, utilitaria de la realidad y de cómo aprovecharla para elevar su inserción política, su legitimidad social y su gravitación económica. La ideología poco o nada cuenta. Así, el canon del cri- men organizado es pragmático. Por ello, es posible discernir una disposición similar en la criminalidad organizada: un apego al statu quo. Más que pretender una transformación estructural, y pese a que utiliza medios violentos, la criminalidad organizada tiende a perpetuar un esquema social y político dado. De allí que su orientación sea conservacionista en el sentido de evitar que se produzca un cambio radical del sistema establecido que afecte sus intereses.

Resumiendo, hoy el crimen organizado alcanza una dimensión integral, opera en un contexto que es funcional a su crecimiento, tiene como objeto prioritario proyectar su dominación, actúa con medios preferente pero no exclusivamente violentos, se apoya en códigos pragmáticos y es portador de una orientación esencialmente reaccionaria. Estos componentes están todos presentes en el caso del crimen organizado que se despliega en América Latina.

A su vez, dos notas principales identifican la evolución y el ejercicio del poder del crimen organizado. Por una parte, éste evoluciona en tres estadios. Tiene una fase "predatoria» inicial que se distingue por la afirmación territorial de grupos criminales que garantizan su poderío por medio de la violencia, y con ello logran defender su empresa ilícita, eliminar rivales, ganar influencia local y asegurar el monopolio privado de la fuerza. Tiene una fase "parasitaria» posterior que implica una sustancial influencia política y econó- 
mica, combinada con una evidente aptitud corruptora. Y tiene un último nivel «simbiótico» cuando para lograr su afianzamiento el sistema político y económico se vuelve tan dependiente del «parásito" -esto es, del crimen organizado- como este de la estructura establecida.

Por otra parte, la modalidad de poder que practica es un asunto precariamente investigado por especialistas $\mathrm{y}$ funcionarios. $\mathrm{El}$ "poder disgregativo" usado por el crimen organizado se manifiesta en una capacidad relativamente difusa pero efectiva de erosionar y derrumbar las instituciones sociales, políticas y económicas establecidas, mediante acciones desafiantes y violentas que ponen en evidencia las deficiencias e injusticias del Estado de derecho.

En América Latina en muchas regiones y localizaciones, en el ámbito rural y el urbano, en zonas ricas y marginales, resulta cada vez más evidente que avanza la fase simbiótica del crimen organizado utilizando su poder disgregativo. De allí la cercanía de que se consolide una pax mafiosa en distintos espacios geográficos sin que nadie en la región y fuera de ella, advierta, aparentemente, que ello ocurre.

\section{UN EJEMPLO EMBLEMÁTICO}

Posiblemente el caso de Colombia resulte hoy el más elocuente en términos de lo que hemos denominado el avance de la pax mafiosa.

Marx decía que la historia se repe- tía dos veces, la primera como tragedia, la segunda como farsa. En Colombia la historia se puede repetir tres veces, la tercera como una devastadora desventura, o puede tomar un giro, un rumbo diferente, edificante y superador.

El actual escándalo de la «parapolítica»-la revelación de un turbio y delictivo entramado de lazos entre los grupos armados de derecha de histórica vinculación con el negocio de las drogas y con sectores latifundistas, segmentos de las clases dirigentes a nivel local, miembros de la elite política nacional y numerosos oficiales de las fuerzas armadas- expresa el tercer episodio en el que el ascenso y consolidación de una nueva clase social criminal se hace evidente. Ante el dilema de contenerla o dejarse cooptar por ella, el Estado colombiano optó en dos ocasiones previas por una particular combinación de represión selectiva, control parcial y convivencia táctica. Para ello, es bueno recordarlo, contó con la tolerancia tácita o la anuencia implícita de Estados Unidos.

Una vuelta al pasado nos puede dar pistas acerca de los potenciales escenarios que hoy enfrenta el país. En 1978 llegó al gobierno el Presidente Julio César Turbay Ayala. Una serie de informaciones y filtraciones pusieron al mandatario a la defensiva en materia de lucha contra los narcóticos, fenómeno que comenzaba a emerger con fuerza. Por un lado, el conocido programa televisivo «60 Minutes» de la cadena CBS develó un llamado Memo- 
rando Bourne (Peter Bourne era Consejero Especial para Asuntos de Salud en la presidencia de Jimmy Carter) en el cual se indicaba que personas cercanas a Turbay, y él mismo, tenían presuntamente conexiones con grupos dedicados al tráfico de drogas. Por otro lado, en 1980 el Washington Post informó -con base en datos provistos por funcionarios estadounidenses en Bogotá- que posiblemente el $10 \%$ del Congreso había sido elegido con dineros del narcotráfico.

En parte por convicción personal y en parte por presión externa, Turbay ordenó desplegar un frontal ataque contra el negocio de las drogas, en aquel momento centrado en torno a la marihuana. Autorizó el derribamiento de aviones, militarizó con más de 10 mil efectivos el departamento (provincia) de La Guajira -contiguo a Venezuela- para acabar con la producción de marihuana, ensayó el uso del paraquat para erradicar esos cultivos, firmó un tratado de extradición que permitía el envío de nacionales a Estados Unidos y se opuso con vehemencia a cualquier iniciativa a favor de la legalización de la marihuana. Ninguna de estas acciones tuvo un efecto decisivo sobre el fenómeno de las drogas. Sin embargo, Bogotá y Washington parecieron, en la época, satisfechos: no más críticas a Colombia a la espera de que se limpiara la casa del «flagelo» de los narcóticos.

Lo que de hecho siguió fue el despegue del procesamiento de coca en cocaína en el país, una feroz campaña del narcotráfico contra funcionarios judiciales, figuras públicas, representantes de la oposición, campesinos en zonas de conflicto y civiles indefensos, al tiempo que el Estado aplicaba la extradición, involucraba a las fuerzas armadas en labores antinarcóticos e iniciaba programas sostenidos de fumigación utilizando el glifosato. En medio de toda esta compleja dinámica de violencia criminal, coerción gubernamental y retaliación de los «narcos», se producían, episódicamente, intentos de diálogo (en 1983 el cartel de Medellín le transmitió ofertas al gobierno a través de encuentros en Panamá con el Procurador General de la Nación, Carlos Jiménez Gómez, y el ex Presidente, Alfonso López Michelsen) y propuestas de mediación (en 1989 los narcotraficantes propusieron que una "Comisión de Notables» auspiciara contactos con el gobierno). La intermitente «guerra contra las drogas» siguió su curso sin resolver el núcleo del problema: un monumental emporio ilícito que se alimentaba de una prohibición cada vez menos eficaz.

Años después la historia parecía revivirse. En 1994 llegó al gobierno el Presidente Ernesto Samper Pizano. Una nueva serie de acontecimientos y denuncias volvieron a colocar a un mandatario colombiano a la defensiva. Por un lado, de acuerdo con revelaciones en el país Samper, supuestamente en persona, habría solicitado y recibido para su campaña electoral 6 millones de dólares del cartel de Cali. Por otro lado, de acuerdo con la Fiscalía colom- 
biana, que inició un vasto proceso judicial al respecto, aproximadamente $65 \%$ del Congreso habría sido electo con dineros del narcotráfico. En ese contexto, y avalando las denuncias y destapes realizados, Washington inició un proceso de acorralamiento político del Ejecutivo: utilizó un procedimiento legal -la certificación anual de un país en materia de lucha contra las drogas- para des-certificar a Colombia (con todas las consecuencias efectivas y simbólicas que ello implicaba) y le retiró en 1996 la visa de entrada a Estados Unidos al Presidente Samper.

Con una mezcla de convencimiento y necesidad, y en el marco de una estrategia estadounidense de exigencias y chantajes, Samper inició una política de mano dura contra los narco-traficantes. Persiguió y desmanteló al cartel de Cali, inició e intensificó masivamente la fumigación con glifosato de plantíos de coca (entre 1994 y 1998 se erradicaron químicamente aproximadamente 150 mil hectáreas de coca) y propuso y logró la reincorporación de la figura de la extradición de nacionales en la Constitución del país. Al final de su mandato Washington se podía sentir satisfecho por todo lo que obtuvo su diplomacia coercitiva. Sin embargo, también era cierto que su política había debilitado notoriamente al Estado colombiano al someter a su presidente a un enorme descrédito y deslegitimación.

Lo que siguió fue el gradual languidecimiento de la estrategia judicial orientada a develar y quebrar el víncu- lo entre la política y las drogas -algo que Estados Unidos no objetó fuertemente. Así entonces, una consecuencia no deseada pero inevitable de lo anterior fue que los narcóticos siguieron siendo el combustible que alimentaba el poder de fuego de los distintos grupos armados. Con ello pudo crecer aún más el lazo entre el paramilitarismo, expresión político-militar de una derecha cada vez más autónoma y decidida a combatir a las guerrillas de las Fuerzas Armadas Revolucionarias de Colombia (FARC) y al Ejército de Liberación Nacional (ELN), y sectores políticos, empresariales y de seguridad en el plano regional. Para buena parte del establishment colombiano lo prioritario era derrotar a la insurgencia. En su evolución, el fenómeno de las drogas se fue transformando: al aumento de los cultivos de coca se añadieron el de las plantaciones de amapola (que se procesaban en heroína), mientras tanto ya no eran tan preeminentes los grandes carteles sino que proliferaron lo que se denominan «boutique cartels» o "cartelitos», organizaciones más reticulares, menos visibles y muy sofisticadas. Paralelamente, el mayor temor de Washington pasó a ser la eventual propagación de lo que Estados Unidos denomina un «estado fallido» en el corazón de los Andes.

Llegamos así a la tercera vez que se repite esta historia en Colombia. En 2002 llegó al gobierno el Presidente Álvaro Uribe. Su abrumadora victoria electoral, su determinación de confrontar militarmente a las FARC, su deci- 
sión de atacar con firmeza al narco-tráfico, su resolución para negociar con las Auto-Defensas Unidas de Colombia (AUC) y su férreo alineamiento con Estados Unidos colocaron en un muy distante segundo plano las dudas que en el país expresaban sectores de la oposición respecto del real desmantelamiento del asunto paramilitar. Dos indicaciones pasaron relativamente inadvertidas en su momento y no opacaron la reelección de Uribe en 2006. Por un lado, el líder paramilitar Salvatore Mancuso indicó que el 35\% del Congreso electo en 2002 estaba constituido por amigos del paramilitarismo. Por otro lado, la National Security Archives, un grupo de investigación no gubernamental que trabaja en la Universidad George Washington logró que se desclasificara un documento de 1991 de la Defense Intelligence Agency (DIA), unidad del Departamento de Defensa estadounidense, en el que se mencionan 104 nombres de figuras prominentes con nexos con el entonces cartel de Medellín: el número 82 era Álvaro Uribe.

Lo anterior no produjo alarma ni en Bogotá ni en Washington porque el mandatario colombiano estaba comprometido con una política recia de seguridad que buscaba evitar el colapso del Estado. Era evidente que el Ejecutivo, que desde 2000 venía implementando el Plan Colombia financiado en parte por Estados Unidos (su aporte supera, a la fecha, los 5.400 millones de dólares), le brindó un impulso adicional a esta estrategia anti- narcóticos con la llegada de Uribe. Según datos disponibles, entre 2002 y 2005 se fumigaron más de $530 \mathrm{mil}$ hectáreas de cultivos de coca y se extraditaron centenares de colombianos (mayoritariamente a Estados Unidos). Cabe destacar, sin embargo, que su efecto en la disponibilidad, precio y pureza de las drogas fue nulo. En 2005 el país continuaba teniendo una producción de 640 toneladas métricas de coca y en 2006 el total de hectáreas con cultivos ilícitos era de 157.000, al tiempo que en Estados Unidos la pureza de la coca se incrementó y el precio cayó a 100 dólares por gramo.

Es en este nuevo contexto que la Corte Suprema colombiana ha comenzado una labor decisiva para desentrañar los vínculos entre el paramilitarismo y la política en el país. Los avances son auspiciosos puesto que se han develado, con base en evidencias, los lazos entre figuras cercanas al Ejecutivo y los comportamientos delictivos del paramilitarismo. Sin embargo, el gran interrogante es hasta dónde se llegará con este escándalo en el que se entrelazan vinculaciones oscuras y criminales que hacen pensar en un gran poder parapolítico en avanzado estado de consolidación.

He ahí el dilema: o la democracia colombiana domestica definitivamente al paramilitarismo o el Estado quedará plenamente corroído por él. Las incógnitas son obvias: ¿Qué hará el Presidente Uribe? ¿Cómo reaccionará Estados Unidos? ¿Cuál es el compromiso de la sociedad? En las dos ocasio- 
nes anteriores en que se presentó la oportunidad de poner la casa en orden muy pocos quisieron o pudieron seguir adelante. Por conveniencia o incompetencia ni Bogotá ni Washington le pusieron coto a una clase social criminal y reaccionaria en franco ascenso. Si se volviese, por tercera vez, a repetir la historia, se habrá instituido una pax mafiosa en el país. Si, por el contrario, se asume con voluntad política, respaldo social y reforzamiento externo, la tarea de frenar y revertir el poder mafioso, entonces posiblemente el país pueda evitar el abismo y asegurar su democracia.

\section{¿Y AmÉRICA LATina?}

El caso colombiano no es único. El enorme poder alcanzado por el crimen organizado en México, la influencia decisiva de la criminalidad ligada a las drogas ilícitas en el Caribe insular, el aumento de la violencia delictiva en América Central, el poderío desplegado por pandillas de narcotraficantes en grandes centros urbanos en Brasil, el persistente nivel de ilegalidad que atraviesa a Paraguay, la incorporación de Sudamérica en muchas rutas internacionales dedicadas al tráfico de narcóticos, el aumento del consumo de sustancias psicoactivas ilegales en varios países de la región y el relativamente fácil lavado de activos en el área muestran que toda Latinoamérica está seriamente aquejada por el auge de la criminalidad organizada. Si lo anterior es verosímil, la pregunta esencial es entonces cuál es el «Estado» de Latinoamérica para hacer frente a tamaño desafío.

Resulta imperioso reconocer la delicada situación actual de América Latina evitando concepciones exculpatorias o teorías conspirativas. Dos tendencias específicas atraviesan la región: la desinstitucionalización y la fragmentación. Ambas dinámicas, de larga data, tienden a agudizarse al comienzo del siglo XXI. La desinstitucionalización se manifiesta en la acumulación de tres décadas perdidas. Durante los años setenta, América Latina vivió una década perdida en términos políticos: la extensión de gobiernos autoritarios en el área -con escasos islotes de limitada democracia-caracterizados por el abuso del poder, el irrespeto de la ley, la violación de los derechos humanos, la eliminación de una generación política de recambio, la desarticulación de los partidos políticos y la desvalorización de la ética pública, significó un enorme debilitamiento institucional. Los años ochenta fueron una década perdida en materia económica: las notas prevalecientes fueron el bajo crecimiento, el alto endeudamiento, mucha volatilidad, creciente informalidad laboral, pobre capacidad tecnológica y desplome de la calidad de vida. A lo largo de los años noventa, Latinoamérica transitó una década perdida en el frente social: se ahondó la desigualdad, se incrementó la pugna entre clases y etnias, se mantuvieron altos los índices de miseria e indigen- 
cia, creció la violencia ciudadana, se multiplicó el desempleo, se descuidó la educación y se deterioró la salud. La democratización de los ochenta y las reformas económicas de los noventa contribuyeron a generar expectativas de cambio positivo que, no obstante, fueron incapaces de producir un viraje decisivo. Muy pocas regiones en el mundo -tal el caso del África subsahariana y de Medio Oriente- exhiben una declinación tan notoria en los últimos treinta años.

La fragmentación se observa tanto en los procesos como en los mecanismos de unidad política, económica y diplomática en la región, por lo cual la categoría Latinoamérica tiende a diluirse. Hoy parece más pertinente hablar de una América del Norte (Panamá, América Central, el Caribe insular, México, Canadá y Estados Unidos) centrada en torno a Estados Unidos en términos de mercado, inversión y migración, entre otros, y una América del Sur (de Colombia hasta Argentina) como una unidad geopolítica distinta. Después del 11/9 la amplia Cuenca del Caribe, que cubre el Caribe insular, Panamá, Centroamérica y México, se ha convertido definitivamente en parte del perímetro de defensa estadounidense y, por lo tanto, la extensión evidente del homeland security de Estados Unidos. Ahora bien, dentro de Sudamérica hay dos realidades: el mundo andino y el Cono Sur. El primero está viviendo hondas turbulencias domésticas y sintiendo el desplazamiento del área de mayor influencia directa de
Estados Unidos que tiene dos escenarios de manifestación crítica: Colombia y Venezuela.

En realidad, en América del Sur es posible efectuar tres cortes zonales. Uno políticoinstitucional muestra una diferencia entre el Arco Andino y el Cono Sur. En los Andes predomina la inestabilidad, los grados de polarización social son altos, la conflictividad es ascendente y las crisis internas de distinto tipo parecen demandar un despliegue de actores exógenos. En el extremo sur del continente los niveles de tensión sociopolítica son aún controlables, la estabilidad se ha preservado, las dificultades económicas y políticas se han ido superando de modo autónomo y la democracia avanza gradualmente.

Una segunda distinción de tipo económico-comercial muestra un contraste entre la Sudamérica del Pacífico y la Sudamérica del Atlántico. Los países que miran al Pacífico -Colombia, Perú y Chile- giran cada vez más hacia Estados Unidos. Tres países del Atlántico -Venezuela, Brasil y Argentina- han pretendido mermar el ritmo de concreción de un eventual ALCA y proyectar una estrategia económica más diversificada y con un rol clave del Estado. Ecuador y Uruguay, a cada lado de los océanos, parecen reorientar su perfil: Quito distanciándose relativamente de Washington; Montevideo acercándose lentamente a Estados Unidos.

Una tercera división en la región tiene que ver con el ámbito militar. En este caso lo que ha existido hasta ahora es una separación entre Argentina, 
Brasil, Chile y Uruguay y el resto de Sudamérica. Estas cuatro naciones han vivido experiencias traumáticas en materia de derechos humanos y quieren preservar una división precisa entre defensa externa y seguridad interna. Como parte de este principio, los gobiernos de estos países rehúsan aceptar la tesis de las "áreas sin gobierno» que puede legitimar acciones de fuerza por parte de Estados Unidos, buscan asegurar el control civil de los asuntos militares y procuran que las fuerzas armadas fortalezcan -y no erosionen-la democracia. El resto de Sudamérica sigue políticas bastante diferentes: no sólo Colombia sino también Venezuela alientan un rol preponderante de los militares en la vida institucional. La tentación del gobierno de Lula en Brasil de involucrar más a las fuerzas armadas brasileñas en tareas de naturaleza policial se divisa en el futuro como un asunto trascendente, por su impacto interno y su efecto de demostración en el área.

En este contexto, la institucionalidad en materia de integración regional se encuentra críticamente debilitada. En términos históricos, la evolución ha sido frustrante ya que los dos pilares de la integración económica -la Asociación Latinoamérica de Libre Comercio (ALALC) y la Asociación Latinoamericana de Integración (ALADI- están, de facto, difuntos; mientras que el que fuera un incipiente espacio de consulta y cooperación económica -el Sistema Económico Latinoamericano (SELA)- ha ido colapsando.
En la actualidad, la Comunidad Andina de Naciones (CAN) se ha desplomado: Colombia y Perú han negociado, bilateralmente, acuerdos de libre comercio con Estados Unidos, Bolivia prefiere inclinarse más hacia el Cono Sur y Venezuela abandonó el esquema de integración que lideró al momento de su fundación hace cuatro décadas. Paralelamente, el Mercado Común del Sur (MERCOSUR) vive un estancamiento inquietante: no ha logrado una mejor institucionalidad y sin evaluarlo suficientemente le ha permitido el ingreso pleno a Venezuela, al tiempo que los dos socios menores -Paraguay y Uruguay- están cada día más tentados a desertar el grupo. Montevideo busca un mayor acercamiento comercial a Estados Unidos y Asunción coquetea con Washington en el campo militar.

Al lamentable estado de los mecanismos regionales mencionados, puede sumarse el de ámbitos hemisféricos e internacionales de habitual significación para el área: la Comisión Económica para América Latina y el Caribe (CEPAL) ha dejado de ser, desde hace tiempo, un referente conceptual e innovador para procesar y proponer un modelo alternativo de crecimiento interno o un esquema audaz de inserción externa mientras que la Organización de los Estados Americanos (OEA) empañó su legitimidad con la elección (y rápida renuncia) de su penúltimo Secretario General y aspira con el nuevo, José M. Insulza, remontar ese déficit. La Comunidad Sudamericana de $\mathrm{Na}$ - 
ciones (CSN), creada en 2004, puede constituirse en un nuevo fracaso para la integración regional si se la concibe de manera grandiosa, con una agenda desproporcionada y sin un enfoque creativo. Si se concibe la CSN como una suerte de fuga hacia adelante ante la parálisis de los procesos de concertación e integración existentes, se estará dando, en realidad, un salto hacia el vacío.

Lo anterior demuestra que las relaciones intra-latinoamericanas adolecen de al menos tres problemas fundamentales. Primero, existe una dificultad de agenda. Las cancillerías del área carecen, en la práctica, de prioridades compartidas. La excesiva vaguedad y la extrema cautela en el tratamiento de los tópicos centrales de la política internacional le han ido restando gravitación y credibilidad a Latinoamérica. Segundo, existe un problema de consenso: la dificultad para arribar a acuerdos fuertes es tremenda. En América Latina es fácil obtener consensos débiles a favor de causas laudables. Sin embargo, hallar una mayoría sólida y solidaria que pueda convertir discurso en praxis ha sido difícil. Lo anterior demuestra que en la región la conjunción de intereses nacionales individuales parece incompatible con un interés colectivo fortalecido. Tercero, existe una cuestión de política exterior. Hoy la inmensa mayoría de las políticas externas latinoamericanas se definen como pragmática. Bien o mal utiliza$\mathrm{da}$, esta calificación encierra dos características salientes: cada país (con las excepciones de Cuba y Venezuela) ha construido, en su propio imaginario, su visión de una especie de «relación especial» (y salvadora) con Estados Unidos (quien no opera con esa lógica) y parece predominar una racionalidad por la cual se piensa que la unidad excesiva con la mayoría de los pares del área disminuye la probabilidad de obtener beneficios de contrapartes con mayor poder. Una simple aplicación de la teoría de juegos indica que a largo plazo las opciones conservadoras que buscan asegurar lo individual, correr pocos riesgos y defender el statu quo culminan mal para todos. Al tradicional divide et impera de Washington se suma la recurrente tendencia intrarregional hacia la desconfianza, el desencuentro y la divergencia en el campo político-diplomático.

En breve, América Latina vive un momento trascendental de desafíos internos y externos en medio de tensiones domésticas notables y fracturas regionales manifiestas. Washington no podrá -y en algunos casos no querráresolver las encrucijadas del área. No hay muchas alternativas para que otros ayuden a enderezar o remedien los propios dilemas: ya no existe la "carta» soviética, la «carta» europea se ha ido desvaneciendo, la «carta» japonesa jamás prosperó y la «carta» china aún no ha llegado. Latinoamérica enfrenta su destino casi solitariamente, algo que no es per se negativo: esta es quizás la hora de soluciones prudentes y efectivas. 
UNA CONCLUSIÓN MODERADAMENTE PESIMISTA

En este sentido, el potencial escenario de una pax mafiosa extendida por toda la región podría ser objeto de más atención y convergencia entre los países del área. Quizás el horror nos una más que el lenguaje o los negocios.

Las dificultades para percibir la evolución de este fenómeno, y, en consecuencia, para precisar políticas orientadas a frenarlo obedecen a tres razones fundamentales. Primero, cabe subrayar la ausencia de una estructura que facilite un diagnóstico serio y compartido en el área. La Comisión Interamericana para el Control del Abuso de Drogas (CICAD) de la OEA no ha tenido la capacidad de gestar este espacio. Es evidente la inexistencia de bases de datos homogéneos y unificados a nivel nacional y regional, la falta de esquemas de análisis sistemático y ponderado de la información disponible y la carencia de una estructura sólida y dotada de prevención y seguimiento del crimen, sea en el marco sudamericano o latinoamericano. Al mismo tiempo las sociedades civiles en el área no tienen acceso a datos, estadísticas, información y análisis sobre los temas de inseguridad pública, lo cual hace imposible una labor mínima de control ciudadano y de exigencia de rendición de cuentas a las autoridades.

Segundo, corresponde destacar la falta de un consenso social y político para enfrentar el tema. Ninguna política pública será eficaz y legítima si no cuenta con respaldo pleno del Estado y de la sociedad civil. Ello exige tejer con paciencia y competencia un consenso ciudadano y partidista en cada país para que las medidas que se apliquen resulten eficaces. La dinámica de los ciclos electorales y la habitual política de negación operan a favor del disenso y la invocación a la «mano dura». Solo la existencia de núcleos más esclarecidos en el Estado y la sociedad pueden llevar a aquella tarea de forjar consensos graduales, puntuales y efectivos. Tercero, es importante subrayar un problema de prioridad muy presente en la región. Una forma de evitar lo anterior es entender que las prácticas exitosas se apoyan en un orden de objetivos preciso: por ejemplo, cortar drásticamente los vínculos de la política con el mundo del crimen; comprender que la mejor política contra la inseguridad es una buena política social (de contención, de educación, de provisión de salud, de atención a los jóvenes, entre otras); y entender que una estrategia contra la criminalidad hace imprescindible la promoción de valores contra la violencia (una ética del trabajo, el imperio de la ley, la no apropiación privada de los bienes públicos, el rechazo de toda forma de arbitrariedad, etc.).

Mientras estas dificultades persisten en el plano de los Estados, aumentan las voces en las respectivas sociedades civiles para adoptar una política más intemperante contra los consumidores de drogas y más coercitiva contra los pequeños traficantes barriales. La ló- 
gica subyacente a ese tipo de estrategia -que equipara erróneamente a un usuario ocasional o frecuente de estupefacientes con poderosas conglomerados mafiosos- es la de una cruzada contra los narcóticos: la idea básica es reforzar una ya fracasada "guerra contra las drogas». Pero el problema medular no es la sustancia, sino su prohibición.

En ese sentido, resulta importante sacar el debate sobre las drogas del terreno dogmático y colocarlo en el campo práctico. No se trata de eludir la controversia valorativa en torno de la cuestión de los narcóticos: en esencia, la polémica sobre las drogas es de naturaleza cultural. Sin embargo, nada indica que sea moralmente más válido continuar combatiendo la "plaga» de las sustancias psicoactivas ilegales que ha mostrado ser totalmente ineficaz; una estrategia anti-prohibicionista puede ser éticamente más sólida si resuelve, en parte, los efectos negativos de las drogas en los individuos, sus familias y la comunidad.

Una alternativa moderada frente a la prohibición militante que no significa la plena legalización es una política de reducción de daños. Esta busca disminuir los graves perjuicios y costos derivados del uso y abuso de las drogas sin recurrir a su erradicación forzada. La lógica explícita de esta política es el reconocimiento de que el fenómeno de las drogas es multifacético e inherente a la condición humana. En consecuencia, su reducción debe ser gradual pero efectiva.

Los supuestos que orientan esta al- ternativa son varios: a) el reconocimiento de que es posible y preferible el uso seguro de drogas en vez de su abuso descontrolado; b) el énfasis en disminuir los grados de violencia asociados con la venta clandestina y el consumo desbordado de narcóticos; c) la búsqueda de la legalidad en todos los ámbitos para eludir el arraigo de estructuras mafiosas a nivel de la sociedad y del Estado; d) el acento en una perspectiva de largo plazo que evite la expectativa de soluciones inmediatas, drásticas y quiméricas; e) el tratamiento más eficaz de la adicción por medio de iniciativas preventivas; f) el hincapié en el desmantelamiento del crimen organizado vinculado al imperio de los narcóticos, así como la desarticulación de los nexos de éste con instituciones y funcionarios estatales; g) la negativa a concebir el asunto de las drogas como una cuestión de seguridad que requiere un tratamiento militar; y h) el rechazo al uso simbólico del derecho que descansa en la noción de que más sanciones -generalmente, inaplicables- van a terminar con el lucrativo negocio de las drogas.

Respecto a las acciones específicas de una estrategia de reducción de daños cabe señalar, entre otros: 1) la adquisición legal por parte de un fondo financiado por los principales centros de consumo y la destrucción simultánea y verificada de las cosechas de cultivos ilícitos por un período determinado (acompañado por una sustitución por productos legales con acceso a los mercados nacional e internacional); 2) 
el establecimiento de un sistema regulatorio, menos punitivo respecto al uso personal de la marihuana; 3) el fortalecimiento de programas que reduzcan los efectos negativos del vínculo entre la aplicación de drogas intravenosas y la trasmisión del SIDA; 4) políticas activas en materia social, educativa y sanitaria dirigidas, principalmente, a los jóvenes, a los sectores menos protegidos y a las familias directamente afectadas por el incremento del consumo y abuso de drogas; 5) la concentración de las políticas disuasivas y restrictivas sobre los grupos mafiosos que son los mayores beneficiarios del negocio ilícito de los narcóticos; y 6) la búsqueda de la cooperación regional e internacional para controlar las estructuras ilícitas que alimentan la empresa de las drogas (por ejemplo, el tráfico de armas ligeras, el lavado de activos, el contrabando, las redes de prostitución infantil, entre otros).

Posiblemente, solo un replanteamiento sustantivo de lo que hasta ahora ha sido la lucha contra las drogas ilícitas y el crimen organizado pueda evitar la consolidación masiva de un pax mafiosa en la región. Probablemente, una lúcida diplomacia ciudadana lleve a los estados del área a reorientar la política actual-individual, inefectiva y vacilante- para frenar el avance de una nueva clase social criminal. Entiendo esta diplomacia como el hecho de que grupos no gubernamentales, no armados, usurpen benignamente un rol tradicional del Estado, asuman una labor de interlocución legítima con distintas contrapartes en el exterior y desplieguen alianzas novedosas con la sociedad civil internacional. Quizás ello conduzca, eventualmente, a superar la confusión de las elites actuales y la indiferencia de la comunidad de naciones. 